\title{
The Omitted Variable In Accounting Education Research: The Non-Traditional Student
}

\author{
Lawrence C. Mohrweis, Northern Arizona University, USA
}

\begin{abstract}
Few studies have examined the empirical question of whether nontraditional students are different than traditional students in learning performance. This study explores this issue. Specifically, is there a performance difference between traditional and nontraditional students in the first course in accounting? The model regressed students' performance (dependent variable) as a function of age (independent variable) along with three controlling attributes: grade point average, gender, and the frequency of class meeting times. The results indicate that nontraditional students performed better than traditional students. This finding has important implications for business education researchers. Educators often engage in quasi-experimental research studies where conclusions are drawn regarding the learning performance of "treatment" versus "control" groups. Researchers should control for the nontraditional variable in their work.
\end{abstract}

Keywords: Nontraditional, Students, Omitted Variable, Principles of Accounting, Maturity Gap

\section{INTRODUCTION}

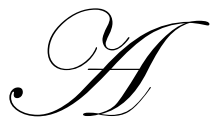

s educators we share a common desire to understand how various attributes either hinder or enhance our students' abilities to learn in our accounting courses (Nelson, et al. 2008). We often test different instructional approaches and teaching methods by setting up treatment and control groups and then drawing conclusions about the value of the new instructional tool or teaching approach (Watson, et al., 2007). In conducting such empirical tests, accounting educators control for those factors that have been shown in the literature to be highly correlated with students' current performance. For example, studies often control for students' GPAs before drawing inferences regarding control versus treatment groups since students' grade history has been shown to be highly related to current performance. However, a factor that has often been omitted by accounting researchers is a variable to control for the difference between traditional and nontraditional students. Many educators are either unaware of the impact of having nontraditional students in their classes or they take the position that nontraditional students are such a small portion of their student populations that they can be safely ignored.

\section{METHOD}

This study explores the impact of the nontraditional variable by examining the performance of students' enrolled in the first course in accounting. Are there differences in learning performance when comparing traditional and nontraditional students? A model regressed students' performance (dependent variable) as a function of age (independent variable) along with three controlling attributes: grade point average, gender, and the frequency of class meeting times. Eighty-three students in two accounting classes, one a two-day-a-week class and the other a threeday-a-week class, provided the data. The average age was twenty-two, the mean GPA was 2.8, and fifty-five percent of the students were male.

As mentioned earlier, a significant predictor of a student's performance in a course is the student's prior academic aptitude. The education literature shows that academic aptitude, as measured by cumulative college grade 
point averages (GPAs), is a strong predictor of expected success in a course (Doran et al., 1991; Hill 1998; Park \& Kerr, 1990; Laband et al., 1997). Laband et al. (1997, page 525) describe GPA as the best measure of students' ability to perform scholastically. Other measures, such as SAT scores, are often "either unavailable or are a noisy signal of academic aptitude." Consequently, GPA was the first control variable added to the model.

Second, gender has often been debated by educators to be an important factor in explaining student performances and perceptions (Tietz, 2007). Ravenscroft \& Buckless (1992) found that when there was a small percentage weight assigned to homework (i.e., 5\%), no difference in course grades was found between female and male students. However, where a larger average percentage weight was assigned to homework (i.e., 11\%) female students were found to have higher course grades than their male counterparts, even though their final exam scores were statistically equivalent. In this study only a small percentage weight of the final course grade was assigned to the homework (less than 5\%). However to error on the side of caution, gender was added as a controlling variable.

Finally, even though the same instructor taught the students, they came from two different classes. One class met on a two-days-a-week schedule and the other class met on a three-days-a-week schedule. The research on class scheduling suggests that this could be a significant factor (Mohrweis \& Pitt, 2010). Therefore, scheduling was added as a controlling variable.

\section{Dependent Variable}

Traditional versus nontraditional student populations are often divided by an arbitrary age criteria. For example, Wooten (1998) considered students over the age of 25 to be nontraditional and then coded the groups with a 1/0 dichotomous variable. The method in the current study was to obtain students' birth dates from official student records and then calculate students' age. The students' actual age, as expressed as a function of months, was entered into the model. In summary, the model can be expressed as follows:

$\mathrm{PERFORMANCE}=b_{0}+b_{1} \mathrm{AGE}+b_{2} \mathrm{GPA}+b_{3} \mathrm{GENDER}+b_{4} \mathrm{CLASS}+e$

where:

PERFORMANCE $=$ Points earned (grade)

AGE $\quad=$ Experimental indicator variable: Age of student (expressed in months);

GPA $\quad=$ Control variable: Cumulative grade point average;

GENDER $\quad=$ Control variable: $1=$ female, $0=$ male;

CLASS $=$ Control variable: $1=$ three-day-a-week classes, $0=$ two-day-a-week classes

The model regressed students' performance (dependent variable) as a function of age (independent variable) along with three controlling attributes. As mentioned earlier, grade point averages, gender, and class scheduling were entered into the model as controlling factors.

\section{RESULTS}

Panel A of Table 1 shows students' performance on a common final multiple-choice objective exam. Age was a significant predictor variable $(\mathrm{p}=0.0405)$ of performance. Consequently, the results show that there was a significant performance difference between traditional and nontraditional students.

Researchers have argued that higher-order learning skills are difficult to assess with objective testing methods (Ingram \& Howard, 1998). Consequently an essay question was given on the final exam as a test of reasoning and critical-thinking skills. The essay question required judgment on the part of the students in deriving an answer that was not purely factual or procedural. Panel B of Table 1 shows the results of the essay question. One student response was deleted from the data set because the question was left blank. Panel B shows that only the students' academic grade history, as measured by their GPAs, was a significant variable. 
Finally, Panel $\mathrm{C}$ of Table 1 shows the total points earned in the class. The regression model was significant with a relatively high adjusted $R$-square $\left(R^{2}=.4618\right)$. Age of the students was a significant variable $(p=0.0037)$.

Table 1: Regression Analyses: Students' Scores as a Function of Age, GPA, Gender, and Class

Panel A: Final exam score (objective questions)

\begin{tabular}{|l|c|c|c|c|c|}
\hline \multicolumn{1}{|c|}{ Source } & DF & Sum of Squares & Mean Square & F Value & Pr $>$ F \\
\hline Model & 4 & 8100 & 2024.97 & 5.64 & 0.01 \\
\hline Error & 78 & 27991 & 358.86 & & \\
\hline Corrected Total & 82 & 36091 & & & \\
\hline
\end{tabular}

Adjusted $\mathrm{R}^{2}=.18$

\begin{tabular}{|l|c|c|c|c|c|}
\hline \multicolumn{1}{|c|}{ Variable } & DF & $\begin{array}{c}\text { Parameter } \\
\text { Estimate }\end{array}$ & Standard Error & t value & Pr $>$ | t $\mid$ \\
\hline Age & $\boldsymbol{1}$ & $\boldsymbol{0 . 1 1}$ & $\mathbf{0 . 0 5}$ & $\mathbf{2 . 0 8}$ & $\mathbf{0 . 0 4 0 5}$ \\
\hline GPA & 1 & 13.95 & 3.16 & 4.42 & 0.0001 \\
\hline Gender & 1 & 3.85 & 4.29 & 0.90 & 0.3724 \\
\hline Class & 1 & 1.02 & 4.51 & 0.23 & 0.8210 \\
\hline
\end{tabular}

Panel B: Final exam score (essay question)

\begin{tabular}{|l|c|c|c|c|c|}
\hline \multicolumn{1}{|c|}{ Source } & DF & Sum of Squares & Mean Square & F Value & Pr $>$ F \\
\hline Model & 4 & 30 & 7.53 & 2.00 & 0.10 \\
\hline Error & 77 & 290 & 3.76 & & \\
\hline Corrected Total & 81 & 320 & & & \\
\hline
\end{tabular}

Adjusted $\mathrm{R}^{2}=.05$

\begin{tabular}{|l|c|c|c|c|c|}
\hline \multicolumn{1}{|c|}{ Variable } & DF & $\begin{array}{c}\text { Parameter } \\
\text { Estimate }\end{array}$ & Standard Error & t value & Pr $>|\mathbf{t}|$ \\
\hline Age & 1 & 0.01 & 0.01 & 1.03 & 0.3067 \\
\hline GPA & 1 & 0.69 & 0.32 & 2.15 & 0.0350 \\
\hline Gender & 1 & 0.82 & 0.44 & 1.84 & 0.0691 \\
\hline Class & 1 & 0.28 & 0.471 & 0.62 & 0.5396 \\
\hline
\end{tabular}

Panel C: Total points earned in the class

\begin{tabular}{|l|c|c|c|c|c|}
\hline \multicolumn{1}{|c|}{ Source } & DF & Sum of Squares & Mean Square & F Value & Pr $>$ F \\
\hline Model & 4 & 106994 & 26748 & 18.59 & 0.01 \\
\hline Error & 78 & 112252 & 1439 & & \\
\hline Corrected Total & 82 & 219245 & & & \\
\hline
\end{tabular}

Adjusted $\mathrm{R}^{2}=.46$

\begin{tabular}{|l|c|c|c|c|c|}
\hline \multicolumn{1}{|c|}{ Variable } & DF & $\begin{array}{c}\text { Parameter } \\
\text { Estimate }\end{array}$ & Standard Error & t value & Pr $>$ |t $\mid$ \\
\hline Age & $\mathbf{1}$ & $\boldsymbol{0 . 3 1}$ & $\mathbf{0 . 1 1}$ & $\mathbf{2 . 9 9}$ & $\mathbf{0 . 0 0 3 7}$ \\
\hline GPA & 1 & 52.37 & 6.32 & 8.28 & 0.0001 \\
\hline Gender & 1 & 6.50 & 8.59 & 0.76 & 0.4522 \\
\hline Class & 1 & -2.57 & 9.03 & -0.29 & 0.7763 \\
\hline
\end{tabular}

Closer examination of the data showed that there was relatively no difference between using a continuous variable for age versus a 1/0 dichotomous variable when the cutoff for age was arbitrarily set at twenty-four. A $1 / 0$ dichotomous variable using the age of twenty-four appears to be a good setting for the traditional/nontraditional classification for the first course in accounting. With the age set at this level the age variable was significant $(\mathrm{p}=$ $0.0040)$ and the overall model still showed a high adjusted $\mathrm{R}$-square $\left(\mathrm{R}^{2}=.4608\right)$. These results compared favorably to those reported on Panel $\mathrm{C}$ of Table 1 when age was coded into the model as a continuous variable. It should be noted that $13 \%$ of the students were age twenty-four or older. 
When the cut-off was arbitrarily set at twenty-five, the age variable was still significant $(p=0.0249)$ but not as significant as when it was set at twenty-four. Two conclusions can be drawn from the manipulations of the age cut-offs. First, researchers have arbitrarily selected the age of twenty-five as the cut-off for stratifying traditional from nontraditional students in the first course in accounting (Wooten 1998, Jones \& Fields 2001). However, the empirical data shows greater justification for the age of twenty-four as the cut-off if researchers employ a one/zero dichotomous control variable in their studies for the first course in accounting. Second, even if only a small percentage of students are nontraditional it may be a dangerous assumption on the part of researchers to omit the nontraditional variable from their studies. Even when less than $9 \%$ of the students were classified as nontraditional students, which was the case when the age cut-off was set at twenty-five, the nontraditional variable was still significant $(\mathrm{p}=0.0249)$.

\section{LIMITATIONS AND CONCLUSIONS}

This study uses age as a proxy variable to classify a student as a nontraditional student. Many factors are reflective of a nontraditional student. Attributes such as (1) being employed full-time while attending school, (2) being a parent, and (3) being married, can be argued as characteristics of a student that should fall outside of the traditional mode. There are limitations if age alone is used to classify nontraditional students. For example, a student could be a fully employed single parent, yet be classified as a "traditional" student, if he or she is below the age cut-off.

Second, this work examined data from only one instructor and only one type of class (Principles of Accounting - Financial). Future research needs to examine whether there would be an observable discrepancy in student learning in a different setting, for example a junior-level or senior-level marketing or management class. The nontraditional variable may not be significant in an advanced business class where there is less of a "maturity gap" between students.

In summary, an essential element for good research is to control for confounding variables. A study where a quasi-experimental test is conducted by comparing students' performance in a treatment versus control group may provide misleading results without due consideration to the nontraditional variable. Educators are encouraged to recognize the importance of the nontraditional variable and, whenever it is appropriate, incorporate this important explanatory variable in the design of their future research studies.

\section{AUTHOR INFORMATION}

Lawrence C. Mohrweis is a Professor of Accounting at The W. A. Franke College of Business at Northern Arizona University.

\section{REFERENCES}

1. Borg, M. O., P. M. Mason, and S. L. Shapiro. (1989). The case of effort variables in student performance. Journal of Economic Education (Summer): 308-313.

2. Doran, B. M., M. L. Bouillon, and C. G. Smith. (1991). Determinants of student performance in accounting principles I and II. Issues in Accounting Education (Spring): 74-84.

3. Hill, M. C. (1998). Class size and student performance in introductory accounting courses: Further evidence. Issues in Accounting Education (February): 47-64.

4. Ingram, R. W., and T. P. Howard. (1998). The association between course objectives and grading methods in introductory accounting courses. Issues in Accounting Education (November): 815-832.

5. Jones J. P., and K. T. Fields. (2001). The role of supplemental instruction in the first accounting course. Issues in Accounting Education (November): 531-547.

6. Laband, D. N., D. L. Rosenberg, and K. J. Smith. (1997). An examination of the performance of transfer versus 'native' students in upper-level accounting courses, Journal of Accounting Education (Fall): 515529 
7. Mohrweis, L. C., and K. C. Pitt. (2010), “Assimilation time as a factor of performance: Impact on a new generation of students, American Journal of Business Education (January): 15-18.

8. Nelson, I. T., V. P. Vendrzyk, J. J. Quirin, and S. E. Kovar. (2008). Trends in accounting student characterisitics: Results from a 15-year longitudinal study at FSA schools. Issues in Accounting Education (August): 373-389.

9. Park, K. H., and P. M. Kerr. (1990). Determinates of academic performance: A multinomial logit approach. Journal of Economic Education (Spring): 101-111.

10. Ravenscroft, S. P., and F. A. Buckless. (1992). The effect of gender on academic performance. Journal of Accounting Education (Spring): 163-179.

11. Tietz, W. M. (2007). Women and men in accounting textbooks: Exploring the hidden curriculum. Issues in Accounting Education (August): 459-480.

12. Watson S. F., Apostolou, B. A., J. M. Hassell, and S. A. Webber. (2007). Accounting education literature review (2003-2005), Journal of Accounting Education (Volume 25): 1-58.

13. Wooten, T. C. (1998). Factors influencing student learning in introductory accounting classes: A comparison of traditional and nontraditional students. Issues in Accounting Education (May): 357-373. 


\section{NOTES}

